\title{
An Energy Efficient Confinement Relying upon Indoor/Outdoor Context for OS Mechanism
}

\author{
C. Geetha, S. Kavitha, S. Sri Gowtham
}

\begin{abstract}
Theoretical-today, there may be paying little thoughts to what you resemble at it usage of flexible applications that endeavor a customer's locale. Significant occupations of area statistics interlace geotagging through strategies for on-line structures affiliation media locales, driver assist and path, and tending to close to districts of hobby. in any case, the primary patron may not get a cope with on the excessive essentialness prices of the use of region courting (to be express the GPS) or might not pick snappy selections concerning whilst to allow or debilitate location affiliations - for example, when inside. consequently, an tool that may pick out these decisions for the achievement of the patron can essentially improve a far off's battery life. in this paintings, we gift a centrality use appraisal of the confinement strategies open on modern-day Android PDAs and recommend the growth of an indoor detainment shape that may be set up depending on whether or not a purchaser supposedly is inner or outdoor. In light of our essentialness appraisal and execution of our proposed shape, we provide take a look at happens - checking battery lifestyles after some time - and display that an indoor requirement framework incited by means of indoor or outdoor setting can refresh cellphone battery lifestyles and, potentially, area precision.
\end{abstract}

Keywords: OS mechanism, wi-fi, GPS

\section{INTRODUCTION}

Zone amass programs concerning modern mobile telephones have gotten relentless use within the present society - to the factor wherein it could also be said that distinctive have ended up being obligated to those forms of occupations. Locale information is used to geotag posts with the aid of techniques for on line structures affiliation media goals, to skip on the area air and information, to attract in clients to research to a pined for zone, and to provide statistics on close to bistros and stores. anyways, clients mechanically need to modify the settlement and backing of these quarter primarily based programs with a PDA's battery lifestyles [1-4].

Current phones routinely offer two key types of selecting a client's region: 1) the GPS and a couple of) a shape based totally approach that usages capabilities like wi-fi and the cellular radio. The tradeoff between those comes all the way down to accuracy as opposed to criticalness. programs that require quality-grained place being made choose to use the

Revised Manuscript Received on August 22, 2019.

C.Geetha, Department of CSE, Bharath Institute of Higher Education and Research, Chennai, Tamilnadu, India

S.Kavitha, Department of CSE, Bharath Institute of Higher Education and Research, Chennai, Tamilnadu, India.

S. Sri Gowtham, Department of CSE, Bharath Institute of Higher Education and Research, Chennai, Tamilnadu, India. stimulated for energy GPS, while applications with dynamically coarse nuts and bolts may additionally use the structure based issuer, which is less careful, yet has constantly clean centrality more stores. The consumer is an exceptional piece of the time empowered to flip area benefits on or off and, with Android telephones, can in like way explicitly associate with zones lower back through the structure primarily based system might not be sufficient correct for considerable functionality of some uses (ex. navigational programs) - for this condition, the GPS will consistently be conveyed paying little regard to circumstance or putting. As such, this prompts an abuse of imperativeness in situations in which the GPS is removed or incorrect, as an example, in indoor conditions or "urban chasms." It have to what's more be seen as that a customer's physical games will affect all shown location based totally applications, even as a consultant's physical activities essentially arise on a for every utility premise. alongside these traces, a structure that can choose choices with appreciate to district relationship in mild of placing what's extra impact all shown zone based applications will obtain important essentialness spares. We supply an appraisal of the two containment frameworks open to present day PDAs and hypothesis that the progression of an indoor confinement process and furthermore the ability to see indoor or outdoor putting can improve battery life and improvement district accuracy. to check this, we whole an indoor/outdoor declaration advantage and an vital indoor lo-calization machine into the region affiliations structure of the Android working shape. In our sport-plan, we execute an indoor/outside assertion shape converted from any other maker's beyond work and whole wi-fi RSS strolling as the model indoor impediment methodology. unavoidably, this kind of indoor obstruction device may be used to begin the purchaser's zone and destiny paintings can base on this factor to in addition increase place accuracy [5-9].

Our commitments are in line with the going with: offer a giganticness use appraisal between A droid's present confinement techniques (GPS and structure based totally) and our proposed course of movement. Put in force a beyond indoor/outdoor divulgence shape as a complete machine benefit in the Android working structure.

- Create every other locale company in the operating structure into which an indoor prerequisite gadget can be imple-mented to interpret the customer's territory in an extravagant and imperativeness fit manner.

- alter the Fused Location Provider API to definitely transfer among the GPS and an indoor-structure district issuer relying as for indoor/outside

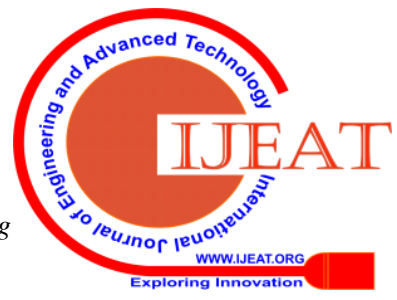


popularity alternate the Fused Location Provider API to authentically transfer between the GPS and an indoor-structure district issuer depending as for indoor/outside reputation.

The paper is overseen as takes after. component II evaluations associated paintings on placing recognizing, essentialness persuading region seeing, indoor obstruction, and Android running shape adjustments. part III offers establishment facts on Android's quarter framework. sector IV offers our criticalness use assessment of Android's gift obstruction structure and what is greater our proposed framework. Fragment V separates our acclimations to the working structure. Bit VI demonstrates our test works out proper to shape. Piece VII discoursed about future studies course and, subsequently, section VIII offers the cease [10-13].

\section{RELATEDWORK}

Our solution crosses 4 fundamental area: trademark putting, criticalness efficient sector spotting, indoor manage, and A droid operating shape changes. deciphering records about the consumer's interest or the earth has a get-collectively of jobs on telephones - an occasion of that's the use of veritable information as a cause for essentialness noteworthy units. improving imperativeness restrict of telephones will continuously be a tireless research region. in addition, the excessive essentialness expenses of utilizing region affiliations make it an attracting region for centrality match modifications. studies on telephones can occur at the application degree, as in making imperativeness fit programs or fashions, or by help imple-mentation into the Android running structure and lower stages, as an example, the Linux segment [14].

\section{RELATEDWORK}

Our solution crosses 4 fundamental area: trademark putting, criticalness efficient sector spotting, indoor manage, and A droid operating shape changes. deciphering records about the consumer's interest or the earth has a get-collectively of jobs on telephones - an occasion of that's the use of veritable information as a cause for essentialness noteworthy units. improving imperativeness restrict of telephones will continuously be a tireless research region. in addition, the excessive essentialness expenses of utilizing region affiliations make it an attracting region for centrality match modifications. studies on telephones can occur at the application degree, as in making imperativeness fit programs or fashions, or by help imple-mentation into the Android running structure and lower stages, as an example, the Linux segment [15].

\section{BACKGROUND}

Furthermore improves zone exactness and criticalness use. Fig. 2 shows the course toward impacting a locale to request the usage of the weaved provider.

For the maximum component, Android software organizers ought to request a territory data from the operating shape by means of unequivocally displaying a zone issuer (usually either the GPS or the framework based issuer) and giving checking out and department requirements. for example, announcing "I need to need to get quarter records from the GPS, at any rate between time of 5 seconds and just if the change in discrete if greater fundamental than 50 meters". be aware: the finding out and department necessities have been really "recommendation" to the running device and might not be respected depending on other applications' region necessities. Fig. 1 displays a streamlined interior depiction of this technique. LocationManager events re-ceive region requests from applications and forward them to the related LocationManagerService. The affiliation oversees area data requests and handles correspondence with the shape's sector companies (GPS and framework). The close by by way of and bit affiliations are ruined for straightforwardness. notwithstanding unequivocally naming a district company to use, architects can use the later FusedLocationProvider B. Indoor/Outdoor Detection Service

The plan of our answer consolidates the execution of the indoor/out of doors id little bit of respiratory area proposed in [16] as an real device advantage in the Android operating shape. We picked their structure for a mixture of motives. no matter the way that there is a amazing deal of studies finished within the discipline of indoor direction, maximum make the supposition that the patron is in an indoor condition once they begin examining. There has now not been a good deal research, mainly not for mobile phones, at the dynamic exposure of indoor as opposed to outside situations. furthermore, the publicity bit of breathing area proposed in [17-20] additionally impelled their structure as a "non explicit affiliation," making an interpretation of it turned into versatile to various plans, (for instance, a running device advantage). eventually, their model system changed into made for Android units and utilized sensors which might be typically open on most Android telephones. along these lines, to the quality of our knowledge, it changed into the high-quality contender structure to use in our solution plan.

In a widespread experience, their structure makes use of the going with 5 equipment fragments to pick whether or not a cell telephone is in one in all three capability states - inside, semi-outside, or outdoor Accelerometer - step-perceiving affirmation to trigger the indoor/out-portal certification.

- Mobile radio - exchange of close to mobile towers' RSS after a while.

- Light sensor - measures ordinary pleasant; detec-tion in putting on time-of-day.

- Magnetometer - measures perils in the region magazine-netic field.

- Proximity sensor - cellphone in-take presentation; used to affirm light sensor readings.

Subordinate upon the purchaser's flexibility, the accumulated statistics (what is greater the present fame) is accrued to enhance the indoor/out of doors repute. Their version structure changed into made as an Android software, yet the residences in their figuring empower it to be completed as a assured gadget advantage without influencing the attestation precision. 


\section{ANALYSIS}

Here, we exhibit a form begin to complete appraisal of most of A droid's constraint techniques and the indoor/out of doors region gain through [1]. table I facts the existing draw of every fabric tools package, got from the maker gave manipulate profile.xml record withdrew from our version contraption, a LG Nexus 5. the prevailing draw for the final 3 sensors are gotten by means of structures for API calls through the sensor advantage.

subsequent, we intestine most of the confinement structures and the indoor/outside disclosure relationship to pick out how mechanically every equipment element is used as a hint of gives to choose to what degree the battery life will ultimate under each. To pick the tools us-age for every check, we use a mix of studying open OS supply code and checking the apparatus use as offered a proof to facilitate Android's battery ability gain (using the dumpsys accumulate). facts offered an explanation to the battery ideal role joins to what degree wi-fi explores closing and when the GPS or sensors switch on or off. with the aid of integrity of the now-unique NetworkLocationProvider, we rely greater on survey the battery gain, but moreover explore powerfully orchestrated supply code open online considering that its ability has in all likelihood not modified basically [22-24].

To examine the battery life for an indoor constrainment shape, we bear in mind a wi-fi RSS growing process which col-lects RSS readings often (for instance on extraordinary occasions every minute). For the vicinity carriers, we separate their hardware use at the same time as referencing region facts on the speediest placing (as an instance a seeing between time becoming for a navigational software). desk II suggests the gear part usage of those tests inside the Breakdown piece. In our seeing of the battery advantage, we discovered that the shape provider, as indicated via commonplace strategy, makes a wireless channel at wellknown interims (on unique activities every minute) if one has now not starting at now happened and, upon any other wi-fi research or an adjustment in mobile nation, furthermore affects a framework to request to vitalize the vicinity. by desires of the GPS and sensors, we found that these regions tirelessly pull in current while use. We moreover join the evaluated battery life for our proposed game plan, which joins the indoor/outside disclosure with an indoor concealment device. As for the breakdowns, if a portion isn't normally inconceivable, a multiplier is available to illustrate the percentage of seconds every minute (by and massive) that the given section is dynamic.

To process the battery life regards showed up within the table, we separate the battery farthest extents of our device (2300 $\mathrm{mAh}$ ) by using the modern drawn by means of most of the assessments, in mild in their mechanical assembly element breakdown. This yields the explored quantity of hours the battery will last. We compare the standard modern-day drawn each minute with the going with circumstance: $\mathrm{n}$

$\mathrm{P}$ ti $*$ pi

$\mathrm{i}=1(1)$
60

wherein $\mathrm{I}$ is a equipment phase, $\mathrm{t}$ addresses to what extent every minute the fragment is used for, and $\mathrm{p}$ addresses the existing draw for that part. moreover, to don't forget an an increasing number of "commonplace" use condition, we issue within the going with hardware components into the battery life figuring and expect they're usually powerful: display screen.complete, wifi.on, radio.on and cpu.active (full magnificence, dynamic CPU use, with both the wi-fi and the phone radio on, besides sit down without shifting). as an example, the "NetworkLocationProvider" take a look at incorporates the going with tough-object components: wifi.test, wifi.lively, display screen.complete, wifi.on, radio.on, cpu.energetic with the going with character current draws p 75.forty eight, 73.24, 221.90, three.five, 2.15, fifty seven.nine and use times three, three, 60, 60, 60, 60. The result of making use of Equa-tion (1) yields a regular contemporary draw of $292.886 \mathrm{~mA}$ and segregating our battery restriction by means of this yields our 7.853 assessed lengthy stretches of battery lifestyles.

by using uprightness of this kind of appraisal, our estimations reflect the higher sure of the criticalness utilization for every take a look at. these calculations do not don't forget sit with out transferring as opposed to dynamic CPU time. incidentally, essentially, the NetworkLocationProvider and the wi-fi growing may have extra sit down CPU time amidst wireless looks. We likewise assume, for inspire, that wireless augmentations or framework income take one minute - as a remaining hotel, they are in a widespread feel shorter. For wi-fi RSS growing, we bear in mind a checking between time of five seconds to assemble RSS regards, but this wide variety can be adjusted for a precision/centrality tradeoff; future paintings can, potentially, pick out logically precise or essentialness suit imperative structures. in the end, we assume the indoor/out of doors unique confirmation to apply moderately more count time (as an instance notable CPU time) from constantly asking about sensor statistics - in like manner, its procedure in the desk under wi-fi RSS developing. close to the day's quit, we anticipate the indoor/outside announcement to carry out continuously horrendous and the wireless RSS interfacing with perform higher, reality be instructed. As regarded, moreover recorded in table II is our proposed territory company: indoor obstacle (for this situation, wireless RSS going) begun via indoor/outoor setting. In mild of the hardware included,

we envision that its centrality use might be limited extra through the indoor/out of doors unmistakable affirmation, instead of with the aid of the RSS jogging. At this second, Android does no longer bear in mind indoor/out of doors placing whilst perceiving sector. table III shows the criticalness keep belongings of the GPS as opposed to our proposed framework relying on the degree of time a customer is internal in an hour. To parent the battery lifestyles for this condition, the regular present day draw every minute is located out as takes after [25].

beyond situation may be adjusted to represent the percent mistake, e: 
ti $*[(1-\mathrm{e}) * \mathrm{pp}+\mathrm{e} * \mathrm{pg}]+$ to $*[(1-\mathrm{e}) * \mathrm{pg}+\mathrm{e} * \mathrm{pp}]($ three $)$ 60

wherein $\mathrm{t}$ speaks to the time spent inner (ti) or out of doors (to), e speaks to the percent mistake, and $\mathrm{p}$ speaks to the everyday draw for our proposed approach (pp) and the GPS (pg). for instance, desk IV shows the hours of battery lifestyles whilst indoor/outside popularity has a mistake price of $25 \%$. The "without mistakes" segment originates from the past desk. No matter the fact that it seems that the battery existence might enhance in instances with much less time spent interior, mistakenly detecting the indoor/out of doors putting could spark off inaccurate place records. The test right here is to successfully determine indoor/outdoor setting without yielding energy effectiveness by way of using an excessive wide variety of gadget elements or computational energy [26].

$\mathrm{m} * \mathrm{pp}+(1-\mathrm{m}) *$

within the occasion that the indoor/outside place is extremely specific, the massive lots of battery life will approach the qualities appeared in desk III. wherein $\mathrm{m}$ tends to the minutes spent internal and $\mathrm{p}$ has a tendency to the commonplace current draw (from our proposed method (pp) and the GPS (pg)). As here to fore, past what many would recollect possible is remoted by using the yielded quantity to get the surveyed battery existence in hours.

Following from this desk, we foresee the volume of time it's going to take the battery to reduce by $1 \%$ underneath our proposed method to connect from 3.668 to 4.330 minutes (thusly, a $10 \%$ drop in battery lifestyles following 36-43 minutes) subordinate upon to what degree the patron spends inner. Every other concept is the indoor/outdoor declaration cooling curacy, as we suggest this to be the trigger for a centrality productive indoor zone companies. In placing on the game-plan of the indoor/outdoor unmistakable confirmation gain in [1], if the structure fails to see the "alternate" among an indoor and out of doors condition, it will no vulnerability be now not in a position alter itself for a long time. For our exam, we are able to understand that the structure won't proper itself amidst indoor/outside changes. In that potential, the

Beneath this circumstance, the standard purchaser can imagine that our device ought to make battery lifestyles by means of to an hour or dynamically thru the scope of the day. Dismissing those imperativeness idea spares, the sector precision internal may be hugely refreshed depending on the performed indoor snag machine.

This sector portrays our improvement situation and our modifications as in line with the Android operating shape for our assessment. Our test joins the usage of an indoor/outside revelation affiliation, ane windoor-based zone supplier, and a distinction within the Fused vicinity provider API to consider the new supplier.

\section{DEVELOPMENT ENVIRONMENT}

A.We build up our fundamental path of motion by using arranging it into the Android Open supply project (AOSP)Android version4.4.2(KitKat).even though we moreover may need to sincerely regulate the Fused area company API, Google Play services is pick out and subsequently, its supply code is closed off. As requirements be, we settle for converting the open-source Fused region accumulating packaged with the AOSP-which is probably steadily settled, but offers an equal handiness: allowing applications to pick accuracy and energy necessities, through then picks the maximum fitting region information problem to the blanketed district providers. Our solution is attempted the LGNexus5smartphone, which highlights a 2.3GHzquad-coreprocessor,2GBofRAM,a2300mAh battery, and all the sensors required by the indoor/outdoor affirmation. The contraption is on a cellular plan without statistics, yet device deals can anyhow be revamped wi-fi. Operating System Modifications: The essential fragment of our evaluation is the utilization of an indoor imprisonment device into the OStosense indoor zones in a energy effective way. blending this kind of trouble framework with indoor/outdoor disclosure in a super world must enhance a contraption's criticalness capability and precision, as regarded in SectionIV. anyhow, we adjust the sport-plan from[1] as a framework association inside the Android running structure making use of source code given by the authors. Our execution makes use of a "boss" magnificence to fill in as recognition person among applications (customers)and the certifiable carrier.We likewise search for after the Observer sample,wherein by exceptional clients can get resuscitates whilst indoor/out of doors placing changes.As a result,our plan for the affiliation reflects the shape of fashionable Android shape institutions and except could supply application fashioners a not unusual gadget to get to indoor/out of doors placing. next, we've made any other locale provider, referred to as the Inferred place provider, because the stage into which any impelled cellular exceptional indoor constraint approach can be implemented(to determine the consumer's domain whilst interior). As referenced, we accomplished a direct dilemma machine subject to Wi-FiRSS widening. using the Android APIs, RSStoallin-amplify APs can be picked up viaa wireless study,

which occurs on this manner or on severa events each second and might in like manner be physically referenced. The usage of the Inferred vicinity provider additionally looks for after a comparable shape as the opposite vicinity providers, GPS and system. This joins adjustments as per the region institutions framework(SectionIII) to engage our new supplier to be gotten to with the aid of techniques for a relative APIs. with the aid of goodness of the kind of indoor restraint technique we picked to execute, we assume absolutely the regions of the APs may be comprehended a safe homes can be seemed upward by way of techniques for an internet database. using the APs'locations and relative separations to the remote picked by techniques for RSS, we utilize hustling to choose the cell cellphone's area. despite the manner that RSS-based totally walking has 
been proven to now not be proper, we are truely making use of it to study the capacity significance spared by using utilising an indoor manipulate method whilst the PDA is seemed to be interior. Our modifications to the working framework are indicated in Fig. three.

Our utilization of the Inferred location provider engages software modelers to unequivocally demand an area from it thusly as distinctive suppliers. anyways, Android in like manner offers the Fused location company API to streamline the method, as referenced in segment III. for this reason, we except present a distinction in the API as joined into the AOSP. In our adjustments, whilst the Fused location company plans to conjure the Gps vicinity provider as appeared with the aid of an application's prerequisites, it except registers to get huge updates from the indoor/outdoor affirmation association. on the off risk that the cellular phone is looked as if it would be internal, the Fused region provider wills witch any gift area needs from the GPS to the Inferred-location company and will switch back if the setting adjustments to outside. In light of this plan, all applications that depend on the Fused region provider API will correspondingly be affected, that is preferred.In respects to execution, the indoor/outdoor exceptional verification association is instantiated upon framework boot, but plays out no work beside at whatever factor delivered with the aid of the Fused location issuer as referenced as much as this time (or besides for in case it is expressly conjured via an engineer). Following our assessment from segment IV, each the exposure affiliation and the Inferred place issuer should purpose a humbler presentation hit than bringing the GPS.In quick, our modifications serve a relative chanism for selecting among place suppliers, to help the patron, in context on indoor or out of doors setting. when you consider that Google asks that utility architects utilize the Fused region provider API to enhance locale precision and decrease power use, our framework can awareness on a monster subset of location installation together programs strolling regarding a purchaser's smartphone.We consider that our answer need to surprisingly reduce significance use. anyways, the exactness (and part of the centrality usage) is based on the stated indoor constraint method. As we have picked a commonly clear repression process, we assume that higher frameworks may be completed to improve an indoor place accuracy [27-30].

\section{FUTUREWORK}

Future work can pivot around improving numerous locales. Regardless, the precision and essentialness ability of the indoor/outside certification may be driven ahead. For this condition, past what many could keep in mind attainable the essentialness sensibility of our affordable Fused Locaiton Provider. The region exactness in like manner largy impacts the essentialness consumption underneath appealing use, as we had conferred in section IV. As selected, we had tried to replace the insistence precision using wireless-based totally estimations and future paintings can refine these frameworks or studies new choices that present them-selves as new sensors are joined into PDAs. in the end, dilemma accuracy may be progressed by way of investigating extra PDA thoughts boggling indoor detainment structures which may be recognized additionally to our wi-fi RSS extending.

\section{CONCLUSION}

In this work, we demonstrated an evaluation of the essentialness eaten up with the aid of Android's predicament technique and proposed a alternate in step with the Android running shape to recall indoor/out of doors placing and pick significantly increasingly more astute selections on which vital framework to use to support the client or software engineer. especially, we alternate the FusedLocationProvider API to exchange among the GPS and an indoor control reasoning depending paying little respect to whether the cellphone is appeared to be inside. Our consequences have proven that the hooked up in-portal/out of doors quarter and an indoor imprisonment approach will drain much less essentialness than the GPS and may likewise be constantly specific in indoor conditions. destiny paintings can look at more and more vital criticalness viable methods to cope with oversee pick indoor/out of doors placing and executing dynamically cautious indoor constrainment systems at the phone kind out.

\section{REFERENCES}

[1] Gowri Sankaran, B., Karthik, B. \& Vijayaragavan, S.P. 2019, "Weight ward change region plummeting change for square based image huffman coding", International Journal of Innovative Technology and Exploring Engineering, vol. 8, no. 10, pp. 4313-4316.

[2] Gowri Sankaran, B., Karthik, B. \& Vijayaragavan, S.P. 2019, "Image compression utilizing wavelet transform", International Journal of Innovative Technology and Exploring Engineering, vol. 8, no. 10, pp. 4305-4308.

[3] Kandavel, N. \& Kumaravel, A. 2019, "Offloading computation for efficient energy in mobile cloud computing", International Journal of Innovative Technology and Exploring Engineering, vol. 8, no. 10, pp. 4317-4320.

[4] Vinoth, V.V. \& Kanniga, E. 2019, "Reversible data hiding in encrypting images-an system", International Journal of Engineering and Advanced Technology, vol. 8, no. 6, pp. 3051-3053.

[5] Selvapriya, B. \& Raghu, B. 2019, "Pseudocoloring of medical images: A research", International Journal of Engineering and Advanced Technology, vol. 8, no. 6, pp. 3712-3716.

[6] Senthil Kumar, K. \& Muthukumaravel, A. 2019, "Bi-objective constraint and hybrid optimizer for the test case prioritization", International Journal of Engineering and Advanced Technology, vol. 8 , no. 6 , pp. 3436-3448.

[7] Kavitha, G., Priya, N., Anuradha, C. \& Pothumani, S. 2019 , "Read-write, peer-to-peer algorithms for the location-identity split", International Journal of Innovative Technology and Exploring Engineering, vol. 8, no. 9 Special Issue 3, pp. 445-447.

[8] Kaliyamurthie, K.P., Michael, G., Anuratha, C. \& Sundaraj, B. 2019 , "Certain improvements in alzheimer disease classification using novel fuzzy c means clustering for image segmentation", International Journal of Innovative Technology and Exploring Engineering, vol. 8, no. 9 Special Issue 3, pp. 599-604.

[9] Kaliyamurthie, K.P., Sundarraj, B., Geo, A.V.A. \& Michael, G. 2019 , "RIB: Analysis of I/O automata", International Journal of Innovative Technology and Exploring Engineering, vol. 8, no. 9 Special Issue 3 , pp. 1019-1022.

[10] Velvizhi, R., Rajabhushanam, C. \& Vidhya, S.R.S. 2019, "Opinion mining for travel route recommendation using Social Media Networks (Twitter)", International Journal of Innovative Technology and Exploring Engineering, vol. 8, no. 9 Special Issue 3, pp. 508-512.

[11] Kavitha, R., Sangeetha, S. \& Varghese, A.G. 2019, "Human activity patterns in big data for healthcare applications", International Journal of Innovative Technology and Exploring Engineering, vol. 8, no. 9 Special Issue 3, pp. 1101-1103.

[12] Pothumani, S., Anandam, A.K., Sharma, N. \& Franklin, S. 2019, 
"Extended VEOT framework - Implemented in a smart boutique", International Journal of Innovative Technology and Exploring Engineering, vol. 8, no. 9 Special Issue 3, pp. 762-767.

[13] Kaliyamurthie, K.P., Michael, G., Krishnan, R.M.V. \& Sundarraj, B. 2019, "Pseudorandom techniques for the internet", International Journal of Innovative Technology and Exploring Engineering, vol. 8, no. 9 Special Issue 3, pp. 915-918.

[14] Aravindasamy, R., Jeffrin Rajan, M., Rama, A. \& Kavitha, P. 2019 "Deep learning provisions in the matlab: Focus on CNN facility", International Journal of Innovative Technology and Exploring Engineering, vol. 8, no. 9 Special Issue 3, pp. 990-994.

[15] Theivasigamani, S., Linda, M. \& Amudha, S. 2019, "Object sensing and its identification \& motion sensing", International Journal of Innovative Technology and Exploring Engineering, vol. 8, no. 9 Special Issue 3, pp. 545-549.

[16] Mary Linda, I., Vimala, D. \& Shanmuga Priya, K. 2019, "A methodology for the emulation of IPv4", International Journal of Innovative Technology and Exploring Engineering, vol. 8, no. 9 Special Issue 3, pp. 848-852.

[17] Velvizhi, R., Priya, D.J., Vimala, D. \& Linda, I.M. 2019, "Increased routing algorithm for mobile adhoc networks", International Journal of Innovative Technology and Exploring Engineering, vol. 8, no. 9 Special Issue 3, pp. 1606-1608.

[18] Sangeetha, S., Anuradha, C. \& Priya, N. 2019, "DNS in real world", International Journal of Innovative Technology and Exploring Engineering, vol. 8, no. 9 Special Issue 3, pp. 937-940.

[19] Geetha, C., Vimala, D. \& Priya, K.S. 2019, "Constructing multi-processors and spreadsheets with SKIVE", International Journal of Innovative Technology and Exploring Engineering, vol. 8, no. 9 Special Issue 3, pp. 516-519.

[20] Yugendhar, K., Sugumar, V. \& Kavitha, P. 2019, "A novel method of univac using fuzzy logic", International Journal of Innovative Technology and Exploring Engineering, vol. 8, no. 9 Special Issue 3, pp. 435-437.

[21] Kaliyamurthie, K.P., Michael, G., Elankavi, R. \& Jijo, S.A. 2019 "Implementing aggregate-key for sharing data in cloud environment using cryptographic encryption", International Journal of Innovative Technology and Exploring Engineering, vol. 8, no. 9 Special Issue 3, pp. 957-959.

[22] Jeffrin Rajan, M., Aravindasamy, R., Kavitha, P. \& Rama, A. 2019, "A novel method of object orientation variation in $\mathrm{C}++$ and java", International Journal of Innovative Technology and Exploring Engineering, vol. 8, no. 9 Special Issue 3, pp. 708-710.

[23] Nayak, R., Dinesh, S. \& Thirunavukkarasu, S. 2019, "A novel method improvement of rapid miner for the data mining applications", International Journal of Innovative Technology and Exploring Engineering, vol. 8, no. 9 Special Issue 3, pp. 457-460.

[24] Sivaraman, K., Krishnan, R.M.V., Sundarraj, B. \& Sri Gowthem, S. 2019, "Network failure detection and diagnosis by analyzing syslog and SNS data: Applying big data analysis to network operations", International Journal of Innovative Technology and Exploring Engineering, vol. 8, no. 9 Special Issue 3, pp. 883-887.

[25] Vimala, D., Linda, I.M. \& Priya, K.S. 2019, "Decoupling online algorithms from erasure coding in DNS", International Journal of Innovative Technology and Exploring Engineering, vol. 8, no. 9 Special Issue 3, pp. 950-953.

[26] Rama, A., Kumaravel, A. \& Nalini, C. 2019, "Preprocessing medica images for classification using deep learning techniques", International Journal of Innovative Technology and Exploring Engineering, vol. 8, no. 9 Special Issue 3, pp. 711-716.

[27] Sangeetha, S., Srividhya, S.R., Anita Davamani, K. \& Amudha, S. 2019, "A procedure for avoid overrun error in universal synchronous asynchronous receiver transmitter (usart) by utilizing dummy join and interrupt latency method", International Journal of Innovative Technology and Exploring Engineering, vol. 8, no. 9 Special Issue 3, pp. 657-660.

[28] Aravindasamy, R., Jeyapriya, D., Sundarajan, B. \& Sangeetha, S 2019, "Data duplication in cloud for optimal performance and security", International Journal of Innovative Technology and Exploring Engineering, vol. 8, no. 9 Special Issue 3, pp. 1156-1158.

[29] Aravindasamy, R., Jeffrin Rajan, M., Sugumar, V. \& Kavitha, P. 2019 "A novel method on developing superblocks and the transistor using apodryal", International Journal of Innovative Technology and Exploring Engineering, vol. 8, no. 9 Special Issue 3, pp. 982-985.

[30] Sasikumar, C.S. \& Kumaravel, A. 2019, "E-learning attributes selection through rough set theory and data mining", Internationa Journal of Innovative Technology and Exploring Engineering, vol. 8 , no. 10 , pp. $3920-3924$.

\section{AUTHORS PROFILE}

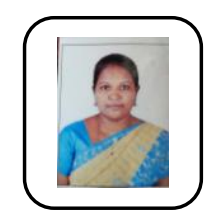

C. Geetha Assistant Professor, Department of Computer Science \& Engineering, Bharath Institute of Higher Education and Research, Chennai, India

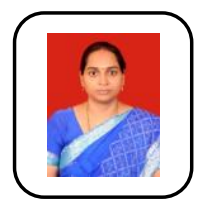

S. Kavitha, Assistant Professor, Department of Computer Science \& Engineering, Bharath Institute of Higher Education and Research, Chennai, India

S. Sri Gowtham, Assistant Professor, Department of Computer Science \& Engineering, Bharath Institute of Higher Education and Research, Chennai, India 